\title{
Aspectos técnicos de manejo utilizados no Sul Catarinense na cultura do milho
}

\author{
Leandro Furlan Cesconetto', Guilherme Doneda Zanini, ${ }^{2}$ Jerffeson Araujo Cavalcante ${ }^{3}$, \\ Paulo Eduardo Rocha Eberhardt ${ }^{4}$ e Ricardo Miotto Ternus ${ }^{5}$
}

\begin{abstract}
Resumo - O milho é uma cultura de destaque no Sul Catarinense, mas a falta de conhecimento adequado ao manejo da cultura impacta na produtividade. O objetivo foi realizar o levantamento das práticas agronômicas utilizadas em propriedades agrícolas produtoras de milho em grão no sul de Santa Catarina e traçar um diagnóstico dos sistemas atuais adotados. Foram aplicados questionários, nos quais adotou-se o modelo das proporções populacionais, que demostrou a necessidade de aplicação de 84 questionários para a obtenção de uma amostra com $95 \%$ de confiança e $5 \%$ de erro amostral máximo, em 20 municípios do Sul Catarinense para avaliar as técnicas empregadas no cultivo e suas implicações produtivas. De forma geral, pode-se constatar que a adoção de práticas de manejo, como espaçamento reduzido, alta densidade de semeadura e manejo de pragas e doenças foram fatores agregadores de produtividade na cultura.
\end{abstract}

Termos para indexação: Zea mays L; Práticas agronômicas; Produtividade.

\section{Technical aspects of management used in southern Santa Catarina in maize crop}

Abstract - Corn is a prominent crop in the southern region of Santa Catarina, but the low knowledge for crop management impacts productivity. The objective was to carry out a survey of the agronomic practices used in agricultural properties producing corn in grain in the south of Santa Catarina and to draw a diagnosis of the current systems adopted. Questionnaires were applied, in which the population proportions model was adopted, which demonstrated the need to apply 84 questionnaires to obtain a sample with $95 \%$ confidence and $5 \%$ maximum sample error, in 20 municipalities in the south of Santa Catarina to evaluate the techniques used in cultivation and their productive implications. In general, it was found that the adoption of management practices, such as reduced spacing, high sowing density and pest and disease management were factors that added productivity to the crop.

Index terms: Zea mays L; Agronomic practices; Yield.

\section{Introdução}

Estima-se que a produção nacional de milho seja de 102 milhões de toneladas de milho na safra 2020/2021, sendo que Santa Catarina responsável por uma área de produção estimada em mais de 431 mil ha (CONAB, 2021). No entanto, mesmo com a evolução gradativa das quantidades produzidas em Santa Catarina em relação à safra 2015/2016, que totalizaram aumentos de $20 \%$ em relação aos rendimentos obtidos, a produção de grãos no Estado ainda não satisfaz a demanda interna de 6 milhões de toneladas por ano em 2016 (CIDASC, 2016).

O milho (Zea mays L.) é uma planta pertencente à família Poaceae e apresenta elevada importância econômica caracterizada pelas diversas formas de utilização, tanto pelo consumo humano quanto por ser empregado na alimentação de animais. Em ambos os casos, algum tipo de transformação industrial ou na própria fazenda pode ser necessário (GARCIA et al., 2006). Segundo Sologuren (2015), o milho é amplamente utilizado para a produção de rações. No Brasil, estimativas apontam que 56 miIhões de toneladas são destinadas para uso na nutrição animal. Assim, a cadeia produtiva do milho tem relevante participação nas cadeias produtivas de leite, ovos, carnes bovina, suína e de aves.

Dentre as derivações de finalidade e utilização que ocorrem quanto ao destino da produção para alimentação animal, podemos citar a produção de silagem e a industrialização do grão de milho em ração. Strazzi (2015) ressaltou ainda que o milho é utilizado, em maior escala, na nutrição animal. Anualmente, no Brasil, mais de 5,5 milhões de toneladas de milho são destinadas para o consumo humano e outras aplicações industriais, além de servir como matéria-prima para uma grande variedade de produtos industriais e alimentícios, como óleo, fermentação de cerveja e extração de etanol entre outros.

No que se refere ao consumo de milho em Santa Catarina, vale lembrar que o Estado é o maior consumidor do Brasil, pois possui o mais avançado parque agroindustrial do país, representado pelas avançadas cadeias produtivas da avicultura e da suinocultura (CIDASC, 2016). A demanda do cereal em Santa Catarina é maior que a produção, o que indica a necessidade de importação de milho de outros estados produtores, tornando o insumo mais caro para os 
produtores rurais e para as agroindústrias (EPAGRI, 2017).

Neste contexto, o objetivo deste estudo foi realizar um levantamento das práticas agronômicas utilizadas em propriedades agrícolas produtoras de miIho para grão no sul de Santa Catarina e traçar um diagnóstico dos sistemas atuais adotados como forma de conhecer e permitir o planejamento e a idealização de práticas de manejo eficientes, assegurando a sustentabilidade e a produtividade de milho na região.

\section{Materiais e métodos}

Foram avaliadas as características técnicas ligadas à produção de miIho no Sul Catarinense durante a safra 2015/2016, utilizando-se amostragem (por meio do protocolo estatístico de densidades populacionais), através da aplicação de questionário pré-elaborado especificamente para este fim, constando 20 questões de múltipla escolha, aplicadas na região geográfica de produção do cereal.

A população amostral contou com 180 pesquisados dos 5.547 produtores ativos na cultura segundo dados do IBGE (2017), em 20 municípios da região sul do estado de Santa Catarina, nos municípios de Araranguá, Praia Grande, São João do Sul, Ermo, Passo de Torres, Sombrio, Santa Rosa do Sul, Meleiro, Morro Grande, Siderópolis, Morro da Fumaça, Jacinto Machado, Turvo, Timbé do Sul, Forquilhinha, Maracajá, Nova Veneza, Criciúma, Içara e Treze de Maio.

Identificado o tamanho da população, estabeleceu-se o método com o auxílio da equação de Pimentel Gomes (2002) para determinação da amostra pelas proporções populacionais. Com isso o número de questionários que deveriam ser aplicados, de acordo com a fórmula:

$$
\mathrm{n}=\frac{N \cdot p \cdot q\left(\frac{Z \alpha}{2}\right)^{2}}{p q\left(\frac{Z \alpha}{2}\right)^{2}+(N-1) E^{2}}
$$

Onde: $\mathrm{n}=$ números de indivíduos a serem amostrados (Produtores de miIho); $\mathrm{N}=$ número de estabelecimentos agropecuários de Santa Catarina nos municípios alvos da pesquisa (5.547 segundo IBGE, 2017); Za/2= Valor crítico que corresponde ao grau de confiança desejado $(95 \%$ - 1,96); p= Proporção populacional de indivíduos que pertencem à categoria estudada. ( $p=0,05769$ tabela); $q=$ Proporção populacional de indivíduos que não pertencem à categoria estudada. ( $q=1-p$, ou seja, 0,9423); $E=$ Erro máximo de estimativa (5\%).

Substituindo os valores:

$\mathrm{n}=\frac{5547 \cdot 0,05769 \cdot 0,9423 \cdot(1,96)^{2}}{0,05769 \cdot 0,9423(1,96)^{2}+(5547 * 1)(0,05)^{2}}$

$\mathrm{n}=82,3$.

Assim chegou-se ao valor $n$ igual a 82,3 após a aplicação da equação, um número que expressa a quantidade de questionários a serem aplicados nos 20 municípios do Estado, com a confiabilidade de 95\% nos dados coletados. Além disso, fez-se necessária à adoção de parâmetros adicionais para definição do número mínimo de agricultores a serem entrevistados em cada um destes 20 municípios, propondo-se um mínimo de 5 questionários aplicados por município envolvidos na pesquisa. A região amostrada foi dividida por proximidade geográfica em três áreas para facilitar o processo de pesquisa e avaliação, sendo assim representadas:

Microrregião 1 - Praia Grande, São João do Sul, Ermo, Passo de Torres, Sombrio, Santa Rosa Do Sul. Microrregião 2 - Araranguá, Turvo, Meleiro, Morro Grande, Timbé do Sul, Maracajá, Jacinto Machado. Microrregião 3 - Criciúma, Nova Veneza, Treze de Maio, Siderópolis, Forquilhinha, Morro da Fumaça, Içara.

O levantamento de dados ocorreu entre 20 de junho de 2016 e 10 de janeiro de 2017, representando dados obtidos até a safra 2015/2016. O conjunto de 20 questões para coleta de dados, expostos da seguinte maneira: (1) Perguntas de caráter social como a faixa etária da população de amostra, a localização geográfica das lavouras, quanto à posse (propriedade) da área explorada para o cultivo, o tamanho da área explorada para produção na safra e assistência técnica; (2) Perguntas de caráter comercial com informações quanto à finalidade do cultivo (grãos e silagem), destino do produto colhido (venda ou consumo); (3) Perguntas técnicas com relação ao manejo cultural com dados sobre e a produtividade média dos últimos três anos, época de semeadura, espaçamento utilizado entre fileiras de semeadura, população de plantas por ha, formas de preparo do solo para se- meadura, coleta de solo para amostragem, aplicação do corretivo calcário nos últimos três anos, aplicação de resíduos orgânicos, práticas de adubação verde, monitoramento e controle de pragas e doenças na cultura.

As respostas dos questionários foram digitadas em um banco de dados (Planilha Eletrônica do Microsoft Excel $\left.^{\circledR}\right)$. A análise dos dados foi realizada a partir de estatística descritiva com medidas de tendência central (média aritmética) e de medidas de variação, baseadas na média geral dos resultados e desvio padrão como unidade de dispersão.

\section{Resultados e discussão}

Pode-se identificar uma tendência de possível falta de sucessão familiar na agricultura no Sul Catarinense impulsionada pelo êxodo rural. Este fenômeno de abandono da vida no campo atinge muitos pequenos agricultores, o que os torna extremamente vulneráveis no que se refere à sua permanência no meio rural.

Os produtores das regiões 1 e 2, em sua maioria, apresentam áreas menores ou igual a 5 ha, sendo estes valores de 49 e $39 \%$, respectivamente. Em contrapartida, $43 \%$ dos produtores de milho da região 3 apresentam áreas entre 10 a 20 ha, e $25 \%$ com áreas maiores ou iguais que 20ha (Figura 1b). Tratando-se da posse da área de cultivo (Figura 1c), constatou-se, para todas as microrregiões do sul do Estado, que os proprietários, em grande parte, mantinham seus cultivos apenas em área própria, com valores variando de 49 a $69 \%$. Porém, a porcentagem de produtores com áreas de terceiros, além da sua área própria, se mostrou elevada, com porcentagem alternando entre 29 e 42.

Dentre as informações avaliadas, a finalidade do cultivo demonstrou que grande parte do cultivo se destina à produção exclusiva de grãos, sendo $58 \%$ dos produtores na microrregião 1 , $75 \%$ na microrregião 2 e $72 \%$ na microrregião 3 (Figura $1 d$ ). Já em relação ao destino dos grãos, em média, independente da microrregião, a maior parte da produção é destinada apenas para a venda, com valor aproximado de $49 \%$. Em contrapartida, cerca de $40,5 \%$ dos produtores, em média, consomem par- 
te da sua produção e vende o superávit do consumo, isso em todas as microrregiões estudadas (Figura 1e).

Quando os produtores foram questionados em relação à época de semeadura, preferencialmente, os produtores da microrregião 1 semearam o milho entre os meses de setembro e novembro ou entre dezembro e fevereiro, sendo este valor de $40 \%$. No entanto, os produtores das microrregiões 1 e 2 têm preferência pela semeadura entre os meses de julho a setembro, sendo que 57 e $53,7 \%$, respectivamente, dos produtores optam por essa época de cultivo (Figura 2a).

$O$ efeito da temperatura do ar e do solo no crescimento e no desenvolvimento da cultura do milho é capaz de alterar o desenvolvimento da espécie, mas devido à baixa altitude predominante na região-alvo do estudo, não há relatos da frequência de ocorrência de eventos climáticos severos provocados por temperaturas inadequadas ao desenvolvimento inicial do stand de plantas. Fancelli (2010) cita que a temperatura do solo, quando inferior a $10^{\circ} \mathrm{C}$ e superior a $40^{\circ} \mathrm{C}$, provoca prejuízo sensível à germinação e que o ideal seria uma temperatura entre 25 e $30^{\circ} \mathrm{C}$.

Quanto ao espaçamento utilizado entre as linhas, o estudo demonstrou que nas microrregiões 1 e 2 se utiliza em maior porcentagem o espaçamento entre 50 e $70 \mathrm{~cm}$. No entanto, na microrregião 3, observou-se comportamento distinto entre as demais regiões, onde o espaçamento mais utilizado é maior que $90 \mathrm{~cm}$ (Figura 2b).

A escolha de espaçamento utilizada pela maioria dos produtores da microrregião 3 (Figura 2b) pode ser determinante na produção final das lavouras, já que essa resposta ocorre porque o miIho não possui um mecanismo de compensação de espaços tão eficiente como outras poaceaes, pois raramente perfiIha, possui baixa prolificidade e limitada capacidade de expansão foliar (ANDRADE et al., 1999), fatores estes que diminuem a produção de fotoassimilados devido à pouca área foliar, resultando em grãos de menor massa.

Em regiões temperadas e subtropicais, as semeaduras feitas no início da estação de crescimento usualmente requerem maiores densidades de plantas (ALMEIDA et al., 2000). Nesses casos, as
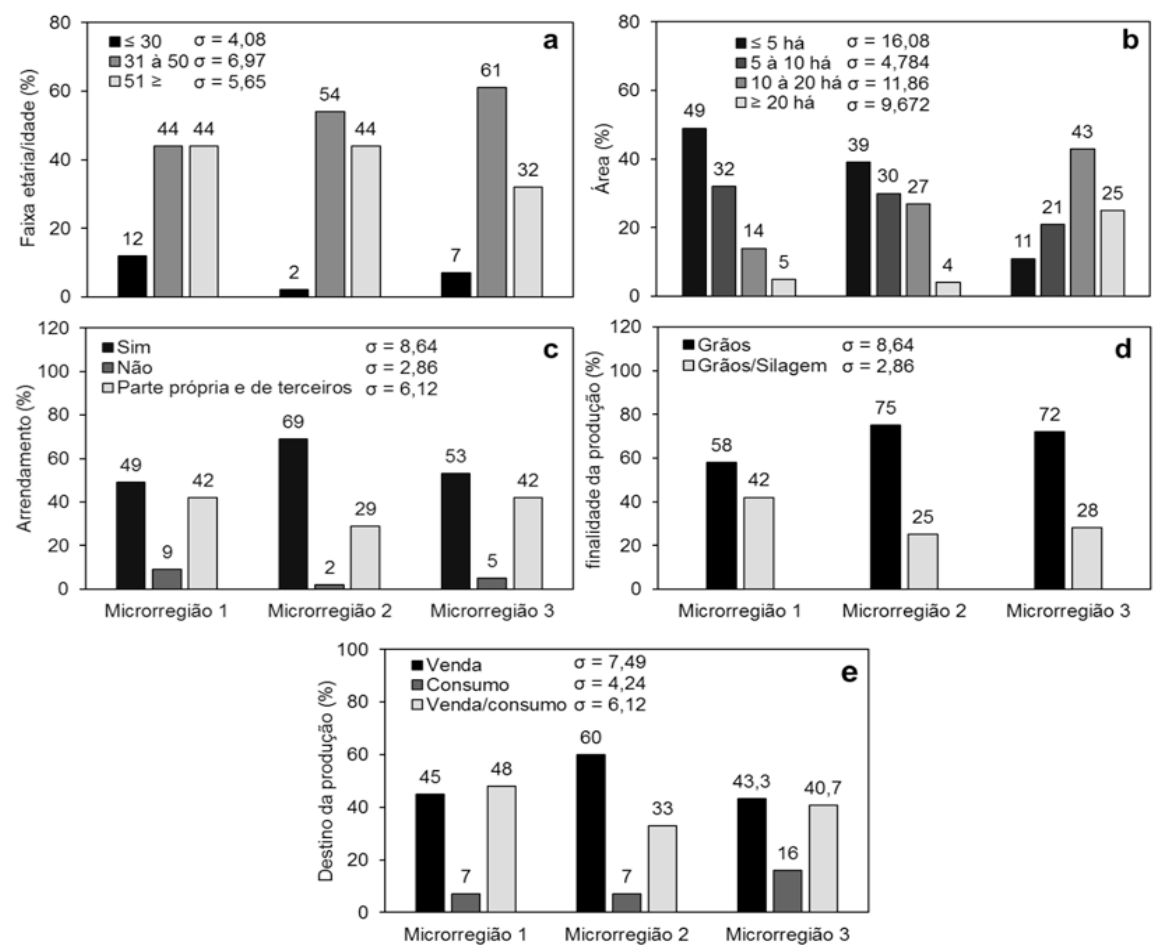

Figura 1. Faixa etária (a), área de cultivo (b), arrendamento (c), finalidade (d) e destino da produção (e) de propriedades rurais produtoras de milho localizadas em diferentes microrregiões no Sul Catarinense

Figure 1. Age group (a), cultivation area (b), lease (c), purpose (d) and destination of production (e) of rural properties producing corn located in different microregions in the south of the State of Santa Catarina
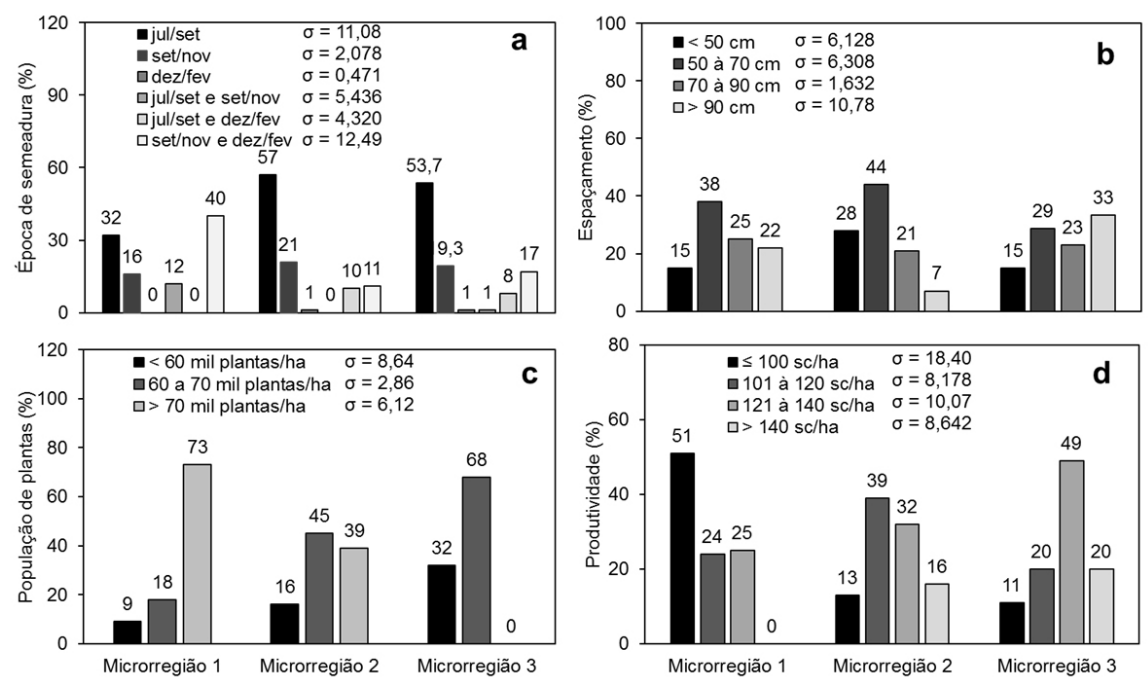

Figura 2. Época de semeadura (a), espaçamento (b), população de plantas (c) e produtividade média (d) de propriedades rurais produtoras de milho localizadas em diferentes microrregiões no Sul Catarinense

Figure 2. Time of sowing (a), Spacing (b), plant population (c) and average productivity (d) of rural properties producing corn located in different microregions in the South of the State of Santa Catarina

temperaturas atmosféricas mais baixas e a menor disponibilidade de radiação solar restringem a expansão foliar e a estatura da cultura, aumentando o número de plantas necessário para otimi- zar a eficiência de uso da radiação solar (SANGOI, 2001).

Já quando se trata da população de plantas mais utilizadas pelos produtores de milho do sul de Santa Catarina, 
observou-se que, para a microrregião 1 , a maior porcentagem se encontra na população maior que 70 mil plantas ha-1, com $73 \%$ dos entrevistados. Esse mesmo comportamento não se repete para as demais regiões, que utilizam, preferencialmente, populações em torno de 60 a 70 mil plantas ha $^{-1}$ (Figura 2c).

Com relação à média de produtividade das lavouras de milho das microrregiões avaliadas, constatou-se que as microrregiões 2 e 3 foram as que apresentaram maior rendimento de grãos. Neste aspecto, observou-se que essas regiões apresentaram 16 e 20\%, respectivamente, áreas com produtividade acima de 140 sacos por hectare (Figura $2 d)$. De modo que os resultados referentes à coleta de solo nos últimos dois anos (Figura 3a), correção do solo (Figura 3b), aplicação de resíduos orgânicos (Figura 3c) e adubação verde (Figura 3d) apresentaram resultados semelhantes, com exceção dos produtores da microrregião 3 , que não realizam correção do solo periodicamente. Já, para as demais variáveis, observou-se que, em média, $79,8 \%$ dos produtores realizam estas práticas de manejo, independente da microrregião (Figura 3).

A correção da acidez do solo é muito importante para a sustentabilidade do uso agrícola do solo, pois um solo ácido compromete o desenvolvimento e a produtividade das culturas. Assim, a calagem tem se destacado como a prática mais utilizada na agricultura para adequar as propriedades químicas do solo às necessidades das culturas (OLIVEIRA et al., 2010).

Poucas práticas agrícolas dão retornos tão elevados como a correção da acidez do solo, no que diz respeito ao aumento da produtividade das culturas (BAMBOLIM et al., 2015). Porém, faz-se necessário que os produtores tornem corriqueira a prática de analisar periodicamente o solo, garantindo assim a obtenção de informações relacionadas às condições físicas e químicas do solo.

Os custos com fertilizantes sintéticos e a melhoria das propriedades do solo (temperatura e humidade) podem favorecer os microrganismos edáficos e proporcionar melhor estrutura e textura do solo, bem como aumentar os teores de matéria orgânica, elevar o pH e adicionar carbono e nitrogênio ao solo. Além disso, a adubação orgânica pode
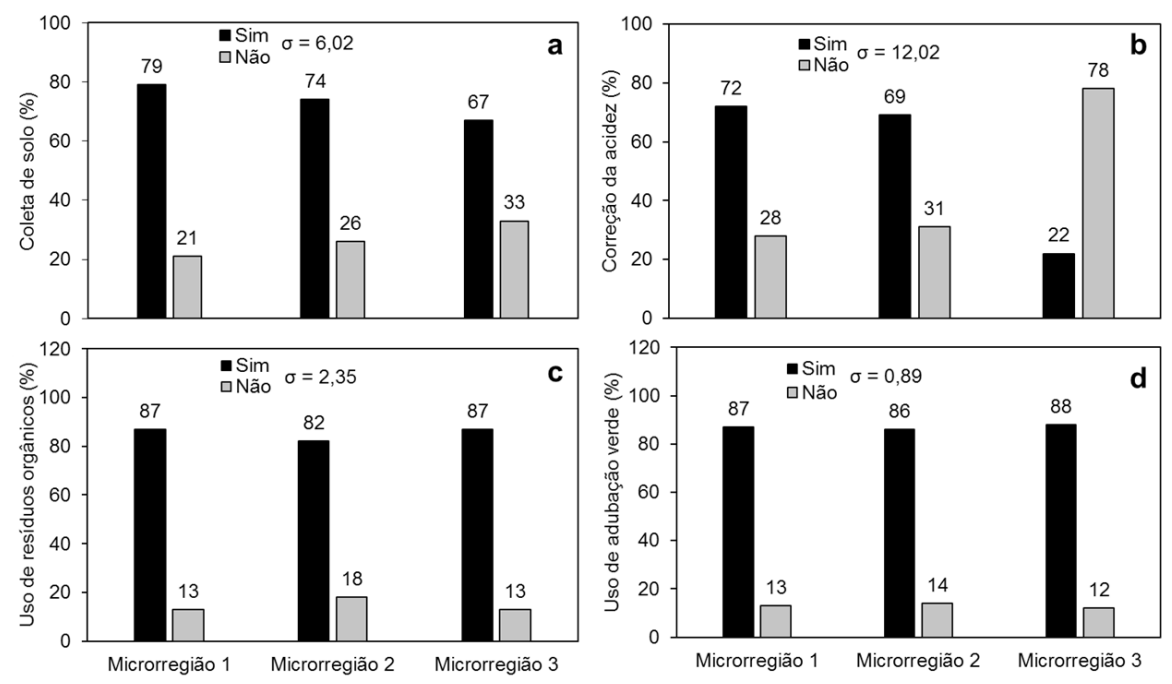

Figura 3. Questionamento se o produtor de milho realiza coleta de solo periodicamente (a), se realiza correção do solo (b), aplicação de resíduos orgânicos (c) e adubação verde (d) em propriedades rurais produtoras de milho localizadas em diferentes microrregiões no Sul Catarinense

Figure 3. Questioning whether the corn producer periodically performs soil collection (a), soil correction (b), application of organic residues (c) and green manure (d) in cornproducing properties located in different microregions in the south of the State of Santa Catarina

contribuir para a melhoria das propriedades físicas, químicas e biológicas do solo (FERREIRA et al., 2012).

Para os dados de monitoramento das lavouras de milho, observou-se que os produtores, em todas as microrregiões avaliadas, não realizam o monitoramento visual da lavoura, sendo que a microrregião 3 foi a que apresentou maior porcentagem de respostas sim em relação às demais microrregiões ( $\mathrm{Fi}$ gura 4a).

No controle de pragas realizado pelos produtores de milho nas microrregiões 1, 2 e 3, pode-se observar que 32, 55 e $46 \%$ dos entrevistados usam sementes com Organismos Geneticamente Modificados (OGMs) com a presença da biotecnologia Bt (Bacillus thuringiensis), respectivamente. Destaca-se ainda que 58 e $48 \%$ dos entrevistados das microrregiões 1 e 2, respectivamente, além de utilizarem a tecnologia Bt, aplicam agroquímicos para a controle das pragas. Já os entrevistados da microrregião 3 ou usam o milho Bt ou o controle químico de maneira individual (Figura 4b).

Cruz et al. (2013) relatam que o método de controle mais utilizado tem sido baseado quase que exclusivamente em produtos químicos, propiciando o aparecimento de populações de pragas resistentes aos diferentes princípios ativos aplicados. Desta forma, enfatiza-se que o uso de cultivares transgênicos de miIho não aumenta a produtividade, o que muda é sua interação com o ambiente, evitando perdas causadas por efeitos bióticos a campo e, mais recentemente, abióticos (MORAIS \& BOREM, 2015).

Outra atividade negligenciada pelos produtores de milho no Sul Catarinense, independente da microrregião, é o uso de sementes tratadas. Em média, 64\% dos produtores dessa região não adquirem sementes com tratamento industrial (Figura 4c). Essa preferência por sementes sem tratamentos pode reduzir significativamente o desempenho das plantas no campo, já que o tratamento de sementes é uma ferramenta tecnológica de grande importância, pois protege as culturas desde a fase da emergência até o início de desenvolvimento, sendo uma prática técnica e economicamente recomendada (AVELAR et al., 2011).

Em contrapartida, o controle de doenças, diferente do tratamento de sementes, bem como do monitoramento da lavoura, é uma prática utilizada por quase $100 \%$ dos produtores de milho em todas as microrregiões analisadas (Figura 4d). Conforme Paschoalati et al. (2015), a cultura está sujeita à ocorrência de várias doenças, afetando a qua- 

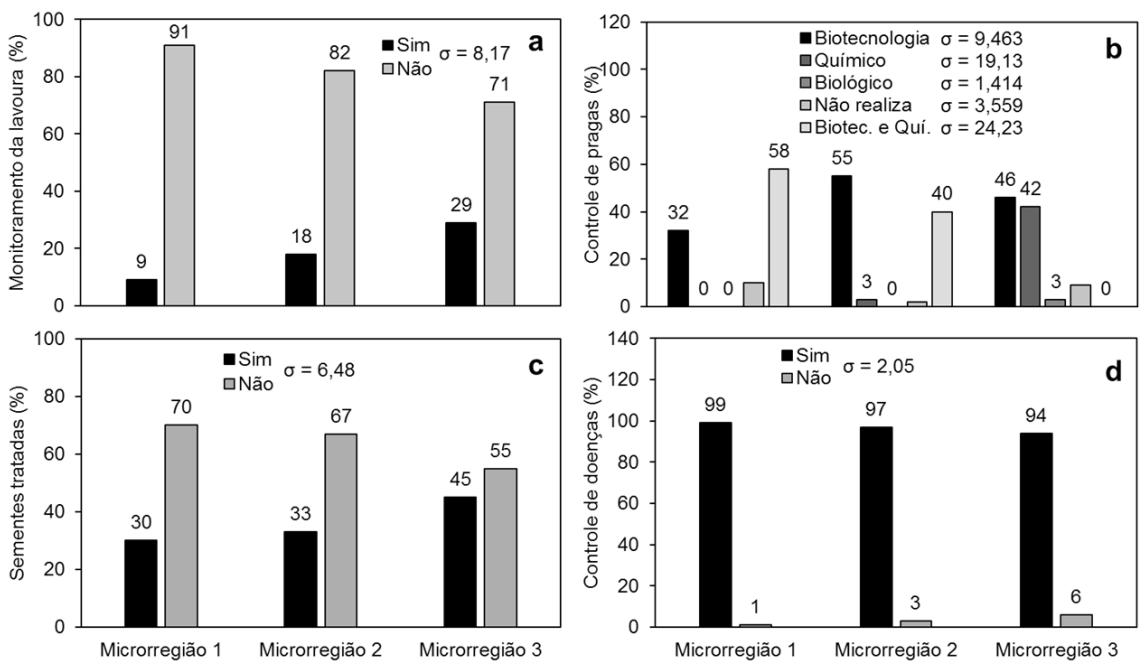

Figura 4. Questionamento se o produtor de milho realiza monitoramento da lavoura (a), se realiza controle de pragas (b), se utiliza sementes tratadas (c) e se realiza controle de doenças (d) em propriedades rurais produtoras de milho localizadas em diferentes microrregiões no Sul Catarinense

Figure 4. Questioning whether the corn producer performs crop monitoring (a), pest control (b), treated seeds (c) and disease control (d) is carried out on rural corn-producing properties located in different microregions in the south of the State of Santa Catarina

lidade e o valor nutritivo de grãos e da forragem, o que pode trazer perdas de produtividade.

\section{Conclusão}

As práticas agronômicas utilizadas na mesorregião Sul Catarinense por produtores rurais como utilização de adubação correta, calagem, controle de pragas e doenças têm contribuído para maiores produções de milho.

O correto espaçamento e o adensamento de plantas, em conjunto com a assistência técnica presente nas propriedades rurais, proporcionaram aumento de produtividade.

\section{Referências}

ALMEIDA, M.L.; SANGOI, L.; ENDER, M. Incremento na densidade de plantas: uma alternativa para aumentar o rendimento de grãos de milho em regiões de curta estação estival de crescimento. Ciência Rural, Santa Maria, v.30, p.23-29, 2000.

ANDRADE, F.H.; VEGA, C.; UHART, S.O. Kernel number determination in maize. Crop Science, Madison, v. 39, p. 453-459, 1999.

AVELAR, S.A.G.; BAUDET, L.; PESKE, S.T.; LUDWIG, M.P.; RIGO, G.A.; CRIZEL, R. L.; OLIVEIRA, S. Armazenamento de sementes de soja tratadas com fungicida, inseticida e micronutrientes e recobertas com políme- ros líquidos e em pó. Ciência Rural, v.41, n. 10, p. 1719-1725, 2011. DOI: http://dx.doi. org/10.1590/S0103-84782011005000130

BAMBOLIM, A.; CAIONE, G.; SOUZA, N. F.; SEBEN-JUNIOR, G. F.; FERBONINK, G. F. Calcário líquido e calcário convencional na correção da acidez do solo. Revista de Agricultura Neotropical, Cassilândia-MS, v. 2, n. 3, p.34-38, jul./set. 2015.

CIDASC. Companhia Integrada de Desenvolvimento Agrícola de Santa Catarina. Santa Catarina, 2016. Disponível em: http://www. cidasc.sc.gov.br/blog/2016/05/24/milho-euma-das-principais-fontes-de-alimento-dobrasileiro-com-importancia-estrategica-nasexportacoes-do agronegócio Acesso em: 30 set. 2017.

CONAB. Companhia Nacional de Abastecimento. Acompanhamento da safra brasileira de grãos - v.1, n.1 Brasília: Conab, 2013. Acesso em: 05 fev. 2021.

CRUZ, I.; VALICENTE, H.F.; VIANA, P.A.; MENDES, S.M. Risco Potencial das Pragas de Milho e Sorgo no Brasil. Minas Gerais, p. 9, 2013.

EPAGRI. Empresa de Pesquisa Agropecuária e Extensão Rural de Santa Catarina, 2017. Santa Catarina. Disponível em http:// docweb.epagri.sc.gov.br/website_cepa/Boletim_agropecuario/boletim_agropecuario_ n52.pdf. Acesso em: 18. out. 2017.

FANCELLI, A. L. Cultivo racional e sustentável requer maior conhecimento sobre planta do milho. Visão Agrícola USP ESALQ São Paulo, ano 9, p.20-23, 2015.

FATORELLI, L.; MERTENS, F. Integração de políticas e governança ambiental: o caso do licenciamento rural no Brasil. Ambiente \& Sociedade, Campinas/SP, v.13, n.2, p.401415, 2010.

FERREIRA, L. E.; Souza, E.P. e Chaves, A. F.; Adubação verde e seu efeito sobre os atributos do solo. Revista Verde de Agroecologia e Desenvolvimento Sustentável. vol. 7, n. 1, p. 33-38. 2012.

GARCIA C. J.; MATTOSO J. M.; DUARTE J. de O.; CRUZ C. Aspectos Econômicos da Produção e Utilização do Milho. Minas Gerais, dezembro, p.5, 2006.

INSTITUTO BRASILEIRO DE GEOGRÁFIA E ESTATISTICA - IBGE, Censo agropecuário, Rio de Janeiro, v.7, p.1-108, 2017.

MORAIS, P. P. P.; BORÉM A. Maior interação com o ambiente eleva uso de cultivar transgênico no Brasil. Visão Agrícola USP ESALQ, São Paulo, ano 9, p.61-65, dez 2015.

OLIVEIRA, C. M. R.; PASSOS, R. R.; ANDRADE, F. V.; REIS, E. F.; STURM, G. M.; SOUZA, R. B. Corretivo da acidez do solo e níveis de umidade no desenvolvimento da cana-de-açúcar. Revista Brasileira de Ciências Agrárias, Recife-PE, v.5, n.1, p.25-31, 2010.

PASCHOALATI, S.F.; MELO, T. A.; DURIGAN DALIO, R. J. Indução de resistência contra patógenos: definição e perspectivas de uso. Visão Agrícola USP ESALQ, São Paulo, ano 9, p.110-112, 2015.

PIMENTEL-GOMES, F. Estatística aplicada a experimentos agronômicos e florestais: exposição com exemplos e orientações para uso de aplicativos. Piracicaba: FEALQ, 2002.

SANGOI, L.; ENDER, M.; GUIDOLIN, A.F.; ALMEIDA, M.L.; HEBERLE, P.C. Row spacing reduction influencing maize grain yield in regions with a short summer. Pesquisa Agropecuária Brasileira, Brasília, v.36, p.861-869, 2001.

SOLOGUREN, L. Demanda mundial cresce e Brasil tem espaço para expandir produção. Visão Agrícola USP ESALQ, São Paulo, ano 9, p.8-11, 2015.

STRAZZI, S. Derivados do milho são usados em mais de 150 diferentes produtos industriais. Visão Agrícola USP ESALQ, São Paulo, ano 9, p.146- 150, 2015. 